\title{
A review of the use of information and communication technologies for dietary assessment
}

\author{
${\text { Joy } \mathrm{Ngo}^{1}{ }^{*} \text {, Anouk Engelen }}^{1}$, Marja Molag ${ }^{2}$, Joni Roesle ${ }^{1}$, Purificación García-Segovia ${ }^{3}$ \\ and Lluís Serra-Majem ${ }^{1,4}$ \\ ${ }^{1}$ Community Nutrition Research Centre of the Nutrition Research Foundation, University of Barcelona Science Park, \\ Baldiri Reixac 4, 08028 Barcelona, Spain \\ ${ }^{2}$ Division of Human Nutrition, Wageningen University, PO Box 8129, 6700 EV Wageningen, The Netherlands \\ ${ }^{3}$ UPV Science Park, Building 8E, Esc. F, Piso 0 Dpcho 02, Polytechnical University of Valencia, Camino de Vera s/n, 46022 \\ Valencia, Spain \\ ${ }^{4}$ Department of Clinical Sciences, University of Las Palmas de Gran Canaria, PO Box 550, 35080 Las Palmas \\ de Gran Canaria, Spain
}

(Received 4 February 2009 - Revised 6 May 2009 - Accepted 1 June 2009)

Presently used dietary-assessment methods often present difficulties for researchers and respondents, and misreporting errors are common. Methods using information and communication technologies (ICT) may improve quality and accuracy. The present paper presents a systematic literature review describing studies applying ICT to dietary assessment. Eligible papers published between January 1995 and February 2008 were classified into four assessment categories: computerised assessment; personal digital assistants (PDA); digital photography; smart cards. Computerised assessments comprise frequency questionnaires, $24 \mathrm{~h}$ recalls (24HR) and diet history assessments. Self-administered computerised assessments, which can include audio support, may reduce literacy problems, be translated and are useful for younger age groups, but less so for those unfamiliar with computers. Self-administered 24HR utilising computers yielded comparable results as standard methods, but needed supervision if used in children. Computer-assisted interviewer-administered recall results were similar to conventional recalls, and reduced inter-interviewer variability. PDA showed some advantages but did not reduce underreporting. Mobile phone meal photos did not improve PDA accuracy. Digital photography for assessing individual food intake in dining facilities was accurate for adults and children, although validity was slightly higher with direct visual observation. Smart cards in dining facilities were useful for measuring food choice but not total dietary intake. In conclusion, computerised assessments and PDA are promising, and could improve dietary assessment quality in some vulnerable groups and decrease researcher workload. Both still need comprehensive evaluation for micronutrient intake assessment. Further work is necessary for improving ICT tools in established and new methods and for their rigorous evaluation.

Diet assessment: Methods: Information and communication technologies: Review

Owing to the complexity of nutrition (and many present health) behaviours, it is essential to assess dietary intake adequately, thus providing reliable data to increase the effectiveness of interventions and policies both at the individual and population level. The classic methods to measure food and nutrient intake (food records, $24 \mathrm{~h}$ recalls (24HR), dietary history and FFQ) have instrument-specific advantages and disadvantages. Disadvantages include, among others, heavy respondent burden requiring subjects to perform difficult cognitive tasks and to be literate. In addition, researchers need appropriate data on food composition ${ }^{(1-3)}$. A recent review in this supplement has showed that the major factors influencing misreporting (under and overreporting) in recall methods are due to the reliance on respondents' memory and ability to estimate portion sizes ${ }^{(4)}$. This may result in the unintentional omission or addition of foods.

\section{Information and communication technology}

Given these recognised limitations, research has focused on refining assessment methods to more accurately evaluate food intake. More recently, the possibilities of developing

Abbreviations: ICT, information and communication technologies; IMM, interactive multimedia; MeSH, medical subject headings; PDA, personal digital assistants; YANA-C, young adolescents' nutrition assessment on computer; DH, diet history; EBIS, diet history, consulting and information system; FIRSSt, Food intake recording software system.

On behalf of EURRECA's RA 1.1 'Intake Methods' members: Serra-Majem L (Coordinator), Cavelaars A, Dhonukshe-Rutten R, Doreste JL, Frost-Andersen L, García-Álvarez A, Glibetic M, Gurinovic M, De Groot L, Henríquez-Sánchez P, Naska A, Ngo J, Novakovic R, Ortiz-Andrellucchi A, Øverby NC, Pijls L, Ranic M, Ribas-Barba L, Ristic-Medic D, Román-Viñas B, Ruprich J, Saavedra-Santana P, Sánchez-Villegas A, Tabacchi G, Tepsic J, Trichopoulou A, van 't Veer P, Vucic V, Wijnhoven TMA.

* Corresponding author: Joy Ngo, fax +34 9340345 43, email nutricom@pcb.ub.cat 
new applications of information and communication technologies (ICT) to improve dietary as well as physical activity assessment are being explored.

The application of ICT in dietary and physical activity assessment offers several potential advantages. Innovative methodological approaches can improve data quality, consistency and completeness. Furthermore, new technologies hold considerable promise for reducing costs as the presence of trained interviewers is not required for a complete interview. Moreover, computerised assessment can save considerable time in data coding as data are immediately stored. Because of less respondent burden, it may be possible to collect long-term data on both food intake and physical activity. New technologies may also help to simplify the self-monitoring process, which increases compliance and validity of selfreported food and energy intake ${ }^{(5)}$.

Subjects' compliance with recording their food intake is often a problem, often due to lack of motivation or difficulties in remembering to register intake. This is especially problematic when subjects are required to keep records for longer periods of time, when the novelty wears off or when the recording process is difficult and time consuming ${ }^{(6)}$.

ICT may enhance intake assessment by simplifying the process and making it less time consuming to monitor food intake, as well as increasing the subject's motivation to complete the task. As such, willingness to record intake may increase and therefore more reliable data are obtained.

The purpose of this literature review was to describe and evaluate the applications of ICT in dietary intake assessment. The aim was to explore a broad range of studies that assessed the use of new as well as renewed technologies to obtain dietary data. The term 'renewed methods' is applied to existing instruments that have incorporated ICT. New methods consist of those that are distinct from the classic methods, which have also focused on the use of ICT to assess dietary intake.

\section{Methods and materials}

A systematic literature search was carried out in Medline to identify articles published between January 1995 and February 2008. The structured strategy included the following keywords and medical subject headings (MeSH) terms applied as follows: ('food' (MeSH) OR diet OR nutrient OR food consumption OR 'food habits' (MeSH)) AND ('nutrition assessment' (MeSH) OR assessment OR methods OR monitoring OR methodology OR analysis OR evaluation) AND (ICT OR technology OR personal digital assistants (PDA) OR computer OR assisted OR internet OR 'information science' (MeSH) OR 'radio waves' (MeSH) OR radio frequency OR photos OR digital).

Titles and abstracts were evaluated to select articles evaluating the use of ICT in new or renewed dietary-assessment methods to assess intake, including studies that applied technology as part of an intervention.

The following exclusion criteria were applied for data selection: ICT not forming part of dietary intake measures, ICT in diet assessment tools that only measured specific food items, ICT in nutrition education tools, studies relating to GM food, food technology or those evaluating technologies applied to hygiene or food safety.
A manual review of reference lists in the selected articles was conducted by the second author to identify additional articles for possible inclusion. Papers were classified according to ICT method and information on administration, user evaluation and validation was extracted.

\section{Results}

The Medline search on ICT and dietary intake assessment yielded 3992 publications. After applying exclusion criteria, fourteen articles were selected. Examination of the reference lists of these articles yielded two additional articles. In total, sixteen articles were included and classified into four assessment categories: computerised assessment; PDA; digital photography; smart cards. Nine studies evaluated the use of computer assisted dietary assessment (including interviewerand self-administered instruments), four reported on PDA, two addressed the use of digital photography and one evaluated the use of smart cards. The study characteristics and results are summarised in tables in the Appendix and further described later.

\section{Renewed classic measurement methods}

\section{Computerised assessment}

ICT was applied in FFQ, 24HR and diet histories. Out of nine papers, three studies utilised computer-assisted self-administered quantitative FFQ, including one that incorporated a reduced FFQ, and three others applied self-administered 24HR. The remaining studies used computer-assisted interview-administered diet histories ( $n$ 2) and 24HR ( $n$ 1).

$F F Q$. An audio computer-assisted self-interviewing questionnaire that recorded data by using a touch screen was developed to collect diet and lifestyle data from the previous 12 months in a population of American Indians and Alaskan Natives ${ }^{(7,8)}$. Recorded audio was utilised, which simultaneously read the text (questions and answers) shown on the screen and the questionnaires could be administered in English, Navajo and Yupik. Out of 604 participants, 97.2\% reported that audio computer-assisted self-interviewing questionnaire was easy to use and $96 \%$ found it to be enjoyable. Although $86.2 \%$ would use this tool again, $62 \%$ said that more directions were needed and $10.6 \%$ had difficulty using it, particularly those with a lower educational level, infrequent computer use and older subjects. The diet history analysis showed $18 \%$ of subjects with high-energy intake $(>33$ $472 \mathrm{~kJ}(8000 \mathrm{kcal})$ or $27196 \mathrm{~kJ}(6500 \mathrm{kcal})$ for men and women, respectively $)^{(8)}$. Validity and reliability of this audio computer-based questionnaire are currently being evaluated.

Another application of a FFQ in a reduced form was seen in a computer-tailored fat intake reduction intervention ${ }^{(9)}$ in 220 adults (20-60 years) that utilised a fat intake FFQ as well as questions about demographics and psychosocial determinants (level of motivation). Most subjects agreed that the questionnaire were comprehensible and easy to complete, according to a five-point Likert scale (3.96 (SD 0.57)). Participants $>40$ years and with higher motivation levels showed greater acceptability of the computerised questionnaire, but no associations were seen for sex, education level and computer literacy. 


\section{$24 \mathrm{~h}$ Recalls}

Self-administered. The young adolescents' nutrition assessment on computer (YANA-C) is a computerised $24 \mathrm{~h}$ dietary recall $^{(10)}$ developed for the self-monitoring of food intake by children 11 years and older. Participants were required to record six eating occasions (breakfast, morning snack, lunch, afternoon snack, dinner and evening snack) using a 400-item food list organised into eighteen food groups. Quantification of intake consisted of selecting from photographs of standard portions for eighty-one items that changed in real time as a response to a 'more' or 'less' button feature. Students positively evaluated YANA-C in an opinion survey. Validation against a 1d-estimated food record and single 24HR interview showed higher estimates for energy and nutrient intakes with YANA-C compared with food records, but no significant differences with the 24HR. Spearman correlation coefficients between YANA-C and the food record were on average 0.62 and between YANA-C and the interview 0.67.

An earlier study also conducted in schoolchildren evaluated a self-administered multiple-pass-computerised 24HR using the Food Intake Recording Software System (FIRSSt) ${ }^{(11)}$. An evaluation questionnaire completed by the study participants yielded a positive review. Validity was tested by comparing the food intake data of 138 fourth-grade children obtained by FIRSSt with data from an observed school lunch and a single $24 \mathrm{HR}$ conducted by a dietitian. The food intake data obtained by the different dietary-assessment methods were compared item per item for matches, intrusions and omissions. Results demonstrated that FIRSSt was slightly less accurate than a dietitian-conducted 24HR. Issues identified included that some children reported a large number of consumed foods and beverages, probably caused by them pressing all buttons in attempts to try out the program's options. Even though this was corrected for and the amount of errors decreased, some uncertainty still remained as to what foods were actually consumed.

In adults, an interactive multimedia (IMM) dietary recall was tested against an interview-administered recall in eighty low-income participants aged 18-65 years (91\% were female), both recalls being realised on the same day ${ }^{(12)}$. The IMM recall included a touch screen and English and Spanish audio files. Breakfast was separated from the other meals and assessed in another IMM section as a separate recall, which caused confusion for some subjects. Nonetheless, $53 \%$ of the participants preferred the IMM recall to the interview-administered recall and a paper and pencil method. Correlation results excluding the breakfast IMM showed a mean of 0.6 for the IMM and the interviewer-administered recall. Noteworthy exceptions were seen for folate $(0.29)$ and alcohol (0.99). In the computerised dietary recall, when four portion size ranges were substituted with standardised portions, the correlations decreased.

Interviewer-administered. The European Prospective Investigation into Cancer and Nutrition (EPIC), a cohort study on diet and cancer in ten countries, applied a two-step computer-assisted $24 \mathrm{~h}$ dietary recall (EPIC-SOFT) in a calibration study to decrease differential measurement errors. To evaluate the standardisation of the 24-h recall, energy intake data from 32063 participants were collected by seventy female interviewers in eight countries ${ }^{(13)}$. For male subjects, no significant differences were found between interviewers in five out of seven countries and for women the results showed no significant differences in four out of eight countries. The difference in log-transformed mean energy intake between centres in the same country was in general NS. Moreover, the percentage of interviewers with obtained mean energy intake within SD $10 \%$ of the country mean energy intake was $98 \%$ for men and $94 \%$ for women.

Dietary history. One study compared two computerassisted interviewer-administered diet history methods (DH and EBIS) against weighed food intake ${ }^{(14)}$. The two diet history methods were similar in structure, but with EBIS the interviewer had more liberty to ask questions. Validation was conducted via $8 \mathrm{~d}$ of weighed food data in twenty hospitalised patients with an average age of 65 years and without special diets, severe diseases or mental confusion. Greater variation was seen for the DH method (mean daily nutrient intake range from $-34 \%$ to $+20 \%$ with mean $\mathrm{SD}=48 \cdot 1 v$. a range from $-35 \%$ to $+15 \%$ with mean $\mathrm{SD}=28 \cdot 1$ for EBIS). The mean of non-adjusted Pearson correlation coefficients was 0.20 for $\mathrm{DH}$ and 0.30 for EBIS. Nutrient intake was underestimated by both computerised tools compared to weighed intake data, which may have reflected the context of recalling intake of hospital and not home-prepared and portioned foods. Estimating portion sizes was reported to be difficult for the patients.

Another interviewer-administered computerised diet history was applied in the Amsterdam Growth and Health Longitudinal Study (AGAHLS), evaluating the development of health, fitness and lifestyle of adolescents in a general population in The Netherlands ${ }^{(15)}$. Participants had already completed seven classic diet history interviews from mean ages of 13 to 32 years. At the mean age of 36 years, a computerassisted diet history interview was used to measure food intake. In both methods, the previous 4 weeks were used as the reference period. To determine the difference in interviewer bias between the two dietary assessment tools, the inter-interviewer variability was assessed for both methods, the classic diet history interview at the mean age of 32 years ( $n$ 436) and the computer-assisted interview at mean age of 36 ( $n$ 352). The results showed that the computerised tool decreased inter-interviewer variability. For macronutrients, energy, calcium, iron and alcohol, no significant differences were found in the data obtained with the computer-assisted interview (ANOVA range: 0.012-3.829).

\section{Personal digital assistants}

A PDA is a handheld computer that can be used for various purposes. This technology has been applied for data collection in medical settings for over 15 years ${ }^{(16)}$. PDA with specifically designed dietary software program can be used to register and self-monitor dietary intake. Subjects are required to record their food intake immediately after consumption by scrolling through a list of foods or by selecting a food group and then a specific food item. After food item selection, portion sizes are entered.

To assess the accuracy of a PDA-based food record, Beasley et al. ${ }^{(17)}$ compared this method with a $24 \mathrm{HR}$ and an observed lunch in thirty-nine adults of mixed ethnic backgrounds. No significant differences were found in measuring energy and macronutrient intake. When comparing the 
data obtained by a PDA with those obtained by the other dietary-assessment methods, Pearson correlations for the 24HR ranged from 0.5 to 0.8 and those for the observed lunch from 0.4 to 0.8 . Incorrect estimation of portion sizes (49\%) constituted the main source of error in the measurement of food intake. Other sources of error were reporting incorrect foods $(25 \%)$, omitting food $(15 \%)$, reporting similar but not identical food $(9 \%)$ and nutrient database differences $(2 \%)$.

In another study, the use of a PDA to monitor food intake did not improve the validity of self-reported energy intake $^{(18)}$. Energy intakes from 7-d-electronic food records were collected over 1 month in sixty-one overweight white adults. Goldberg cut-off values (1.06 and 2.30 for females, 1.05 and 2.28 for males) were used to classify individual subjects as low energy, valid or overreporters. The premise that self-monitoring via PDA could increase compliance and data validity (by decreased underreporting) was not supported by the results. The use of a PDA for dietary self-monitoring did not decrease the prevalence of low-energy reporting $(41 \%)$ compared with what was found in the literature $(27-47 \%)$.

\section{Personal digital assistant with camera and mobile phone card}

PDA with camera and mobile phone card can be used to record individual dietary intake by taking photos instead of manually recording foods and beverages before and after consumption. Photos are subsequently sent to a dietitian to estimate and analyse daily nutrient intake.

The validity of a PDA with camera and mobile phone card (Wellnavi $^{\mathrm{TM}}$ instrument) was evaluated by comparing daily nutrient intakes obtained by this instrument to those obtained by weighed food records ${ }^{(19,20)}$. Of energy and thirty-two nutrients, researchers found no significant differences between daily nutrient intakes obtained by Wellnavi ${ }^{\mathrm{TM}}$ and those obtained by $1 \mathrm{~d}$ weighed food records, with the exception of $\mathrm{Zn}, \mathrm{Mn}$, vitamin E, SFA, PUFA and dietary fibre. Spearman correlation coefficients comparing the results obtained from the two methods for thirty-three nutrients ranged from 0.21 to 0.86 with a mean correlation coefficient of 0.62 . Study participants reported that the Wellnavi ${ }^{\mathrm{TM}}$ instrument was the least burdensome and least time consuming; however, the twentyeight study subjects were all female college students majoring in food and nutrition ${ }^{(19)}$. In another study in seventy-five normal weight and obese adults, Wellnavi ${ }^{\text {тм }}$ was compared with $5 \mathrm{~d}$ weighed food records and the results showed lower but significant Spearman correlations $(0.32-0.77$; mean $0 \cdot 47)^{(20)}$. However, daily nutrient intakes measured with the Wellnavi $^{\mathrm{TM}}$ instrument were significantly lower than the weighed records. In reference to the evaluation of underreporting in obese subjects, when using Wellnavi ${ }^{\mathrm{TM}}$, this association was found in obese men but not in obese women ${ }^{(20)}$.

\section{Digital photography}

Digital photography is similar to the direct observation of food selection and plate waste, but instead of observers being present in the dining room, food selection and plate waste are photographed with a digital video camera. Reference portions are first determined, weighed and photographed for comparison with photos of participants' trays, the latter photographed at the end of the cafeteria line and post consumption. In order to accurately estimate portion size and plate waste, participants' trays and reference portions should be photographed at the same angle. All photos of reference portions, food selection and plate waste are stored on a computer and can be viewed simultaneously by researchers. An individual's food selection is estimated based on portion size and plate waste as a percentage of the reference portion.

Studies have found that different observers had a high rate of agreement for the estimation of food selection, portion sizes and food intake when using digital photography ${ }^{(21,22)}$. The validity of digital photography for estimating food portion sizes and plate waste was tested by comparing this tool with direct visual estimation in a laboratory setting with adult subjects. Sixty meals consisting of ten different portion sizes from six different university cafeteria menus were prepared and weighed. For each method, three observers independently estimated portion sizes as a percentage of a standard serving. The results supported the validity of digital photography as well as direct visual observation. Although comparable results were found in both methods, Pearson correlations referring to direct visual estimation (0.95-0.97) were often significantly higher than those referring to digital photography (0.89-0.94). Data obtained by both methods showed small overestimates or underestimates. The intra-class correlation coefficients were 0.94 for food selection, 0.80 for plate waste and 0.92 for food intake, confirming high levels of agreement between the observers ${ }^{(21)}$.

In evaluations of sixth-grade children (mean age 11.7 years), digital photography was found to be valid for measuring forty-three schoolchildren's food intake in a naturalistic setting ${ }^{(22)}$. Data were obtained from five consecutive days of school lunches with two dietitians estimating food selection, plate waste and intake using digital photography. Results showed a significant association between food intake as estimated using digital photography and adiposity, which supported convergent validity. Discriminant validity was supported by non-significant correlations between food intake and depressed mood and self-esteem measures. Reliability was confirmed as the two dietitians demonstrated a high degree of agreement in estimations. The intra-class correlation coefficients for kilocalories selected and plate waste were both 0.95 and 0.930 for total kilocalorie consumption. In addition, CI widths were calculated for the $5 \mathrm{~d}$ included in the study and showed that using digital photography for $3 \mathrm{~d}$ was sufficient to obtain a representative measurement of food intake ${ }^{(22)}$.

\section{New measurement methods to assess food intake}

\section{Smart card}

Smart cards can be employed, among other functions, as payments for meals. The smart card is allocated a certain monetary value that can be spent in participating cafeterias or restaurants. When the consumer pays for a meal using the smart card, the foods on the tray are immediately recorded at the cash desk and sent to a central computer. Through this, information can be collected not only about food choices, but also about the date and time of the transaction, costs incurred and the smart card number. Subsequently, the data are stored on the computer and can be linked to a nutrient database. 
Lambert et al. ${ }^{(23)}$ tested the feasibility and accuracy of the smart card used as a tool to measure the eating behaviour of school children. In a school cafeteria, food choices of 198 boys aged 7-11 years were recorded by the smart card system as well as direct observation by researchers in a subsample of sixty-five children, weighing leftover edible foods. During a total period of $10 \mathrm{~d}$, the foods on 265 trays were recorded and the data obtained by both dietary-assessment methods were compared. The results showed an accuracy rating of $95.9 \%$. The largest part of error was caused by the smart card recording no data, although the child had actually consumed a school meal. Another source of identified error was those data recorded by both the smart card and the researcher were not similar. Researchers hypothesised that this occurred as diners exchanged foods or trays or paid for each other's meal.

The present study also tested the variation in portion size and plate waste, and examined the relationship between food choice and food intake. As expected, the results showed that portion sizes as well as plate waste varied significantly. Data obtained by the smart card system provided accurate information about food choice, but not about food or nutrient intake. It would be possible to ascribe an edible wastage correction factor for each food item in the software database; however, the authors viewed this as a time-consuming task $^{(23)}$.

\section{Discussion}

\section{Computerised assessment}

Self-administered computerised assessment makes it possible for participants to register and assess their dietary intake at their own pace and convenience. The subject immediately stores data and interviewers do not have to be present during the entire interview, which saves considerable time and decreases costs. Furthermore, computerised assessment tools can directly calculate nutrient intake and energy expenditure, which makes it possible for immediate feedback ${ }^{(24,25)}$.

However, some subjects may need more instructions before or during completion of the questionnaire. Applying alerts to warn subjects of improbable answers could also decrease the problem of overreporting as well as reduce the amount of data cleaning by researchers. These types of questionnaires may be useful for web-based data collection and could be applied as an alternative to in-person or self-administered questionnaires in studies where participants attend a central studyvisit site, as well as for questions on sensitive topics. When using computerised self-assessment, questions about risky or sensitive behaviours may be answered more truthfully ${ }^{(7)}$. In addition, adolescents might be more motivated to report their dietary intake with computer use ${ }^{(10)}$. With the application of recorded audio to complete a computerised-dietary questionnaire or recall, literacy problems can be decreased.

Interview-administered computer-assisted diet histories and 24HR decreased inter-interviewer variability due to standardised questioning protocols. Moreover, there was a good agreement between the data obtained by the computerised and the classic methods. However, the EPIC study results showed problems still existed in the standardisation of the multiplepass $24 \mathrm{HR}$. Further research was needed to compare the actual validity of $24 \mathrm{HR}$ intakes across centres using urinary $\mathrm{N}_{2}$ and $\mathrm{K}$ as gold standards, so as to estimate the magnitude of systematic measurement errors across the EPIC centres ${ }^{(13)}$.

A disadvantage of self-administered computerised assessment is that it requires the user to have a minimum level of knowledge about computer use. Certain population groups may have difficulty using a computerised assessment tool, for example, older and less educated individuals ${ }^{(7)}$. This is less problematic in interviewer-administered computerised assessment tools.

\section{Personal digital assistants}

PDA-based food records have several advantages as individuals can be provided with immediate feedback and data stored on the PDA can be reviewed at any point in time. Uploading data to a computer allows the researcher or dietitian to analyse dietary intake as often as the user provides them with information. PDA-based self-monitoring greatly decreases the burden of the researcher or dietitian, as the time required to analyse food records is reduced by removing the need for data entry ${ }^{(17)}$. Another advantage with respect to paper diaries is that it is possible to date and timestamp every recorded food item, which makes it possible to avoid fallacious results on adherence ${ }^{(17-26)}$. Furthermore, audible alarms make it possible to alert the participant at specific times to record food intake.

Although the advantages of PDA show their potential to improve data quality, there are several limitations. The use of PDA-based food records increases the respondent burden compared with paper diaries. Studies report subjects having difficulty using the search function and experienced inability to find certain foods ${ }^{(27-29)}$. Furthermore, like paper diaries, PDA-based food records require participants to be literate. As such, older or less educated individuals might have difficulty using a PDA for recording food intake. However, although limited in size, a pilot study in a group of older participants with no prior computer experience showed that they easily learned how to use a PDA ${ }^{(26)}$. Despite certain obstacles, studies demonstrated that PDA can simplify intake registration and self-monitoring, thus increasing the quality of dietary-intake data. As this dietary-assessment tool still has limitations, further development of PDA and dietary software program is necessary.

In regards to studies using PDA with a camera, dietitians could not always accurately estimate portion sizes as subjects took photos at the wrong angle and digital photo images were inadequate. The accuracy of this method can be increased by improving the quality of the digital photos and by including a PDA-based food list for users to select the foods and drinks consumed. More research is needed to determine whether this method can be used in other and more diverse population groups.

\section{Digital photography}

The main advantage of digital photography is the possibility to collect dietary intake data from large groups relatively quickly, with minimal disruption and impact on the eating behaviour of participants. Because data are immediately stored on the computer, the researchers have more time to analyse and process the obtained data. Furthermore, the participants' identities can be kept anonymous, which can be seen as an advantage. 
Studies show that digital photography is a reliable and valid tool to measure food intake in dining facilities both in adult- and school-age populations. More research is required on the practical usability and the amount of observations needed to obtain reliable food-intake data. In addition, further investigation should address whether this tool can be used to measure dietary intake in different target populations.

\section{Smart card}

An advantage of using the smart card system to measure food choice is that it can collect long-term data from large groups on individual food behaviour. Furthermore, the costs are relatively low as smart cards are inexpensive and fewer researchers are needed since data are stored when the diner uses the smart card to pay for the meal.

However, the smart card-based system also has limitations in its usability as a dietary assessment method. Lambert et al. ${ }^{(23)}$ observed that children exchanged trays or paid for each other's meal. Furthermore, diners could buy foods and beverages for consumption at a different time. As such, the application of this tool is better indicated to collect information about subjects' food selection and not their food intake.

Results support the usability and reliability of the smart card used as a tool to record food choices in eating facilities. Further research should focus on how the smart card system can be improved as an instrument to measure food consumption. Since the study sample included in this review consisted only of boys between the ages of 7-11 years, more research is needed to determine whether this tool can be applied to measure food intake in a variety of population groups.

\section{Conclusion}

Several dietary-assessment tools applying ICT have been developed and some have shown to be valid and reliable for diverse purposes and target groups. Certain methods, particularly computerised tools and PDA, have the potential to accurately measure dietary intake and may improve dietary assessment quality in certain vulnerable groups and decrease workload of researchers. Both still need further development to improve validity and reliability for the comprehensive assessment of micronutrient intake. Further work is necessary for improving ICT tools in established and new methods and for their rigorous evaluation. The forthcoming results of a recent European Commission project, Innovative Dietary Assessment Methods in Epidemiological Studies and Public Health (IDAMES) ${ }^{(30)}$, should shed light on this topic. In general, which tool is the most suitable to collect dietary data depends on study objectives and the target group. Before selecting a given tool, it is important to review the advantages and disadvantages of each method.

\section{Acknowledgements}

The studies reported herein have been carried out within the EURRECA Network of Excellence (www.eurreca.org), financially supported by the Commission of the European Communities, specific Research, Technology and Development Programme Quality of Life and Management of Living
Resources, within the Sixth Framework Programme, contract no. 036196. The present report does not necessarily reflect the Commission's views or its future policy in this area. J. N. developed the search strategy, supervised and undertook analysis and wrote the final draft of the paper. A. E. carried out the search strategy, contributed to writing of first draft and commented on following drafts of the paper. J. R., P. G.-S. and M. M. commented on drafts of the paper. L. S.-M. participated in the planning of the strategy, directed and supervised the work and commented on all drafts of the paper. Additional support from Dr. Margaret Ashwell and Dr. Janet Lambert in reviewing concepts and contents is gratefully acknowledged. The authors have no conflict of interests to report.

\section{References}

1. Thompson FE \& Byers T (1994) Dietary assessment resource manual. J Nutr 124, 2245S-2317S.

2. Patterson RE \& Pietinen P (2004) Assessment of nutritional status in individuals and populations. In Public Health Nutrition, pp. 66-82 [MJ Gibney, BM Margetts, JM Kearney, L Arab editors, on behalf of the Nutrition Society]. Oxford: Blackwell Science.

3. Rutishauer IHE (2005) Dietary intake measurements. Public Health Nutr 8, 1100-1107.

4. Poslusna K, Ruprich J, de Vries JHM, et al. (2009) Misreporting of energy and micronutrient intake estimated by food records and 24 hour recalls, control and adjustment methods in practice. Br J Nutr 108, (Suppl. 2), S73-S85.

5. Kroeze W, Werkman A \& Brug J (2006) A systematic review of randomized trials on the effectiveness of computer-tailored education on physical activity and dietary behaviors. Ann Behav Med 31, 205-223.

6. Gibson RS (2005) Principles of Nutritional Assessment, 2nd ed. New York: Oxford University Press.

7. Edwards SL, Slattery ML, Murtaugh MA, et al. (2007) Development and use of touch-screen audio computer-assisted self-interviewing in a study of American Indians. Am J Epidemiol 165, 1336-1342.

8. Slattery ML, Murtaugh MA, Schumacher MC, et al. (2008) Development, implementation, and evaluation of a computerized self-administered diet history questionnaire for use in studies of American Indian and Alaskan native people. $J \mathrm{Am}$ Diet Assoc 108, 101-109.

9. Vandelanotte C, Bourdeaudhuij de I \& Brug J (2004) Acceptability and feasibility of an interactive computer-tailored fat intake intervention in Belgium. Health Promot Int 19, 463-470.

10. Vereecken CA, Covents M, Matthys C, et al. (2005) Young adolescents' nutrition assessment on computer (YANA-C). Eur J Clin Nutr 59, 658-667.

11. Baranowski T, Islam N, Baranowski J, et al. (2002) The food intake recording software system is valid among fourth-grade children. J Am Diet Assoc 102, 380-385.

12. Zoellner J, Anderson J \& Gould SM (2005) Comparative validation of a bilingual interactive multimedia dietary assessment tool. J Am Diet Assoc 105, 1206-1214.

13. Slimani N, Ferrari P, Ocké M, et al. (2000) Standardization of the 24-hour diet recall calibration method used in the European Prospective Investigation into Cancer and Nutrition (EPIC): general concepts and preliminary results. Eur J Clin Nutr 54, 900-917.

14. Landig J, Erhardt JG, Bode JC, et al. (1998) Validation and comparison of two computerized methods of obtaining a diet history. Clin Nutr 17, 113-117. 
15. Bakker I, Twisk JWR, Mechelen van W, et al. (2003) Computerization of a dietary history interview within the Amsterdam Growth and Health Longitudinal Study. Eur J Clin Nutr 57, 394-404.

16. Koop A \& Mosges R (2002) The use of handheld computers in clinical trials. Control Clin Trials 23, 469-480.

17. Beasley J, Riley WT \& Jean-Mary J (2005) Accuracy of a PDA-based dietary assessment program. Nutrition 21, 672-677.

18. Yon BA, Johnson RK, Harvey-Berino J, et al. (2006) The use of a personal digital assistant for dietary self-monitoring does not improve the validity of self-reports of energy intake. J Am Diet Assoc 106, 1256-1259.

19. Wang DH, Kogashiwa M \& Kira S (2006) Development of a new instrument for evaluating individuals' dietary intakes. $J$ Am Diet Assoc 106, 1588-1593.

20. Kikunaga S, Tin T \& Ishibashi G (2007) The application of a handheld personal digital assistant with camera and mobile phone card (Wellnavi) to the general population in a dietary survey. J Nutr Sci Vitaminol (Tokyo) 53, 109-116.

21. Williamson DA, Allen HR \& Martin PD (2003) Comparison of digital photography to weighed and visual estimation of portion sizes. J Am Diet Assoc 103, 1139-1145.

22. Martin CK, Newton RL \& Anton SD (2007) Measurement of children's food intake with digital photography and the effects of second servings upon food intake. Eat Behav 8, $148-156$.
23. Lambert N, Plumb J \& Looise B (2005) Using smart card technology to monitor the eating habits of children in a school cafeteria: 1. Developing and validating the methodology. J Hum Nutr Diet 18, 243-254.

24. Lagerros YT, Mucci LA \& Bellocco R (2006) Validity and reliability of self-reported total energy expenditure using a novel instrument. Eur J Epidemiol 21, 227-236.

25. Evers W \& Carol B (2007) An Internet-based assessment tool for food choices and physical activity behaviors. J Nutr Educ Behav 39, 105-106.

26. Burke LE, Warziski M, Starrett T, et al. (2005) Self-monitoring dietary intake: current and future practices. J Ren Nutr 15, 281-290.

27. Welch J, Dowell S \& Johnson CS (2007) Feasibility of using a personal digital assistant to self-monitor diet and fluid intake: a pilot study. Nephrol Nurs $J$ 34, 43-48.

28. Yon BA, Johnson RK, Harvey-Berino J, et al. (2007) Personal digital assistants are comparable to traditional diaries for dietary self-monitoring during a weight loss program. J Behav Med 30, 165-175.

29. Ma Y, Olendzki BC, Chiriboga D, et al. (2006) PDA-assisted low glycemic index dietary intervention for type II diabetes: a pilot study. Eur J Clin Nutr 60, 1235-1243.

30. IDAMES: Innovative Dietary Assessment Methods in Epidemiological Studies and Public Health, http://nugo. dife.de/twiki41/bin/view/IDAMES/ProjectDescription (accessed December 2008). 
Appendix: Characteristics of selected studies on dietary-intake assessment and ICT

Table S1. Computerised assessment

\begin{tabular}{|c|c|c|c|}
\hline First author & Objective & Sample characteristics & Methods \\
\hline \multicolumn{4}{|l|}{ FFQ self-admin } \\
\hline $\begin{array}{l}\text { Edwards et al. } \\
(2007)^{(7)}\end{array}$ & $\begin{array}{l}\text { Development, usability } \\
\text { and acceptability of } \\
\text { ACASI for native } \\
\text { Americans. }\end{array}$ & $\begin{array}{l}\text { Usability subset } n 604 \\
\quad(32.8 \% \mathrm{~m}, 67.2 \% \text { f; aged } \\
18->69 \text { years; } 75 \% \text { aged } \\
18-49 \text { years; self-identified } \\
\text { as American Indian or Alaska } \\
\text { native; } 27.8 \%<\text { high-school } \\
\text { education). }\end{array}$ & $\begin{array}{l}\text { Analysis based on baseline study data, } \\
\text { auxiliary background data and short } \\
\text { usability questionnaire (using five- } \\
\text { item Likert scale) after monitoring } \\
\text { food intake, physical activity, medical } \\
\text { history and other lifestyle data with } \\
\text { ACASI. }\end{array}$ \\
\hline $\begin{array}{l}\text { Slattery et al. } \\
(2008)^{(8)}\end{array}$ & $\begin{array}{l}\text { Descriptive evaluation of } \\
\text { a FFQ (DHQ) using } \\
\text { ACASI in a population } \\
\text { of American Indians } \\
\text { and Alaskan natives. }\end{array}$ & $\begin{array}{l}\text { Six thousand and six hundred } \\
\text { and four study participants } \\
\text { (self-identify as American } \\
\text { Indian or Alaska native, } \\
36.0 \% \text { men, } 64 \% \text { women; } \\
\text { aged } 18->65 \text { years; } 60 \% \\
\text { aged younger than } 45 \text { years; } \\
22 \% \text { with less than a high- } \\
\text { school education, } 6 \% \text { college } \\
\text { graduates). }\end{array}$ & $\begin{array}{l}\text { Completion of audio computer-assisted } \\
\text { interview; anthropometric measure- } \\
\text { ments, blood pressure and a finger } \\
\text { stick blood draw. }\end{array}$ \\
\hline $\begin{array}{l}\text { Vandelanotte } \\
\text { et al. }(2004)^{(9)}\end{array}$ & $\begin{array}{l}\text { Investigate acceptability } \\
\text { and feasibility of an } \\
\text { interactive computer- } \\
\text { tailored fat intake inter- } \\
\text { vention in a general } \\
\text { population. }\end{array}$ & $\begin{array}{l}\text { Two hundred and twenty partici- } \\
\text { pants ( } 20-60 \text { years of age) } \\
67 \% \text { university or college } \\
\text { education. }\end{array}$ & $\begin{array}{l}\text { Participants completed a computerised } \\
\text { questionnaire about demographics, } \\
\text { fat intake and psychosocial determi- } \\
\text { nants, and received personal fat } \\
\text { intake advice. } \\
\text { An evaluation questionnaire was com- } \\
\text { pleted during and after the tailored } \\
\text { program. }\end{array}$ \\
\hline \multicolumn{4}{|l|}{ 24HR self-admin } \\
\hline $\begin{array}{l}\text { Vereecken et al. } \\
(2005)^{(10)}\end{array}$ & $\begin{array}{l}\text { Assess the relative val- } \\
\text { idity and acceptability } \\
\text { of the computerised } \\
\text { 24HR YANA-C. }\end{array}$ & $\begin{array}{l}\text { Study } 1 \\
136 \text { pupils of two secondary } \\
\text { schools (12-14 years of age). } \\
\text { Study } 2 \\
101 \text { pupils of two primary } \\
\text { (11-12 years of age) and two } \\
\text { secondary schools (12-14 } \\
\text { years of age). }\end{array}$ & $\begin{array}{l}\text { Study } 1 \\
\text { Completed 1-d- EFR and the following } \\
\text { day YANA-C (both under supervi- } \\
\text { sion). One week later, YANA-C was } \\
\text { administered a second time. } \\
\text { Study } 2 \\
\text { Completed supervised YANA-C and } \\
24 \mathrm{~h} \text { dietary recall interview on the } \\
\text { same day. A subsample completed a } \\
\text { survey on PC experience, general } \\
\text { attitude towards computers and their } \\
\text { acceptability of YANA-C. A five-point } \\
\text { scale was used. }\end{array}$ \\
\hline
\end{tabular}

Results

Correlation study/validated

$96.0 \%$ of participants found ACASI questionnaires enjoyable to use, $97.2 \%$ reported ease of use and $82.6 \%$ preferred ACASI for future questionnaires.

$62 \%$ indicated more directions were needed $10.6 \%$ reported to have difficulty using ACASI. Lower educational level and less frequent computer use in past year associated with usability difficulty.

Almost $100 \%$ of participants had complete DHQ data. More difficulties seen with lower education and acculturation levels as well as younger men and the unemployed. Low underreporting based on reported energy intake, but $18 \%$ reported suspect high non-alcoholic energy intake ( $>33472 \mathrm{~kJ}$ (>8000 kcal) or $29176 \mathrm{~kJ}$ (6500 kcal) for men and women, respectively) Average time to complete questionnaire was 36 min.

Participants rated the diagnostic tool positively. (Likert scales were 3.96 (SD 0.57) and 4.17 (SD 0.58)). No significant differences were found according to sex, education levels and computer literacy. Significant differences were found between age groups and stages of change.

No

Matches between YANA-C and standard methods ranged from 67 to $97 \%(x=90 \%$ EFR; $89 \%$ with interview) $\kappa$ statistics $0.38-0.92(x=0.73$ and $0.70 \mathrm{EFR}$ and interview, respectively). Mean Spearman correlations for YANA-C and EFR 0.62 and 0.67 for YANA-C and interview. In comparison with EFR, on average $56 \%$ were classified into same tertile and $6 \%$ into the opposite tertile, whereas $61 \%$ were classified into the same tertile and $5 \%$ into the opposite tertile with the interview. 


\begin{tabular}{lll}
\hline First author & Objective & Sample characteristics \\
\hline Baranowski & Assess the validity and & $n 138$ school children (mean \\
et al. (2002) ${ }^{(11)}$ & accuracy of the mul- & age 9.6 years; $33.7 \%$ Euro- \\
& tiple-pass 24HR using & American, $30.4 \%$ African- \\
& FIRSSt. & American, $14.5 \%$ Hispanic \\
& & and $21.4 \%$ other).
\end{tabular}

Zoellner et al. Examine the validity of $(2005)^{(12)} \quad$ an IMM dietary recall when compared wi wh interview-administered dietary recall. (24HR).

24HR interviewer-admin Slimani et al. Examine the level of $(2000)^{(13)} \quad$ standardisation of a computer-assisted 24HR (EPIC-SOFT).
Eighty low-income English- and Spanish-speaking participants (91\% female; ages $18-65$; $28 \%<$ high-school education).

Thirty two thousand and sixty three subjects from ten countries participating in EPIC calibration study.
Diet history interviewer-admin

Landig et al. Validate two compu$(1998)^{(14)} \quad$ terised-assisted interviewer-admin methods of obtaining a diet history (EBIS and DH).

Bakker et al. $(2003)^{(15)}$
Comparison of interviewadministered CAFTF with similar FTF interview and effect on interviewer bias. $n 20$ hospitalised patients $(12 \mathrm{~m}$, $8 \mathrm{w}$; mean age 65 years, range $47-74$ years)

Exclusion criteria: severe diseases, more than $2 \mathrm{~d}$ of fasting, mental confusion and special diets.

$n$ 436, mean age 32 (FTF). $n$ 352, mean age 36 (CAFTF). $n 82$ subjects agreement analysis.
Methods

Results

Correlation study/validated

Comparisons between FIRSSt (not specified if supervised), school lunch observations and a dietitian-conducted multiple group design was used to test obsergroup design was used to test observation and sequencing affects, as well as hair samples. Questionnaire evaluating FIRSSt.

Participants completed both an IMM recall (minimal guidance) and an interview-administered recall consecutively on the same day.

Participants were asked to complete brief opinion survey. A five-point Likert scale was used.

Seventy interviewers in ten countries administered two-pass computerassisted 24HR. Differences in energy intakes across interviewers were compared, adjusting for potential confounders.

Comparison of actual intake (weighed daily amounts of food consumed) to data from two computerised interviewer-administered diet history methods.

Intake of macronutrients and ten micronutrients evaluated and percentage difference calculated.

Data from cross check FTF interview at cohort mean age of 32 years compared to data collected with new cross check CAFTF tool at cohort mean age of 36 years, both referring to prior 4 week intake. Data compared from eighty-two subjects interviewed by FTF at 32 years and at 36 years by a different interviewer using CAFTF to test agreement.
FIRSSt $v$. observation: Accuracy: $46 \%$ match, errors: $24 \%$ intrusion, $30 \%$ omission rates. 24HR $v$. observation: 59,17 and $24 \%$, respectively. FIRSSt $v$. 24-h recall: 60,15 and $24 \%$, respectively. Obtaining a hair sample reduced the omission rate for FIRSSt $v$. 24HR and increased the match rate for $24 \mathrm{HR} v$. observation. Children generally enjoyed using FIRSSt.

Mean of unadjusted correlation coefficients for IMM and 24HR was 0.6. (notable exceptions folate 0.29 and alcohol 0.99). $53 \%$ of participants preferred IMM, $39 \%$ preferred an interviewer and $8 \%$ preferred a pencil/paper method. Mean time of completion: $12.5 \mathrm{~min}$ (IMM) v. $20 \mathrm{~min}$ for $24 \mathrm{HR}$ (completion + analysis).

For men, no significant differences were found between interviewers in five out of seven countries and for women no significant differences in four out of eight countries. The difference in mean energy intake between centres in the same country was in general NS. The percentage of interviewers with a mean energy intake within (SD 10 ) \% of the country mean energy intake was $98 \%$ for men and $94 \%$ for women.

Mean daily intake of nutrients calculated by $\mathrm{DH}$ deviated from $-34 \%$ to $+20 \%$ (mean $\mathrm{SD}=48.1$ ) and from $-35 \%$ to $+15 \%$ (mean $\mathrm{SD}=28.1 \%$ ) with EBIS

Nutrient estimates calculated from both methods tended to underestimate intakes, possibly due to the context of recalling hospital prepared foods.

ANOVA CAFTF 0.012-3.829 and for FTF 1.42211.583.

Yes

The paired-sample differences, standard deviations and $P$-values showed some differences. Pearson's correlation coefficients $0.6-0.9$.

All intra-class coefficients in range of 0.6-0.9. $\kappa$ ranged from 0.4 to 0.8 . Bland-Altman plots showed no relevant differences.

Self-admin, self-administered; ACASI, audio computer-assisted self-interviewing questionnaire; DHQ, diet history questionnaire; 24HR, 24h recall; YANA-C, young adolescents' nutrition assessment on computer; EFR, estimated food record; FIRSSt, food intake recording software system; IMM, interactive multimedia; interviewer admin, interviewer administered; EPIC, The European Prospective Investigation into Cancer and Nutrition; NA, not applicable; DH, diet history, EBIS, diet history, consulting and information system; CAFTF, computer-assisted face-to-face diet history interview; FTF, face-to-face. 
Table S2. Personal digital assistant (PDA)

\begin{tabular}{|c|c|c|c|c|c|}
\hline First author & Objective & Sample characteristics & Methods & Results & $\begin{array}{l}\text { Correlation } \\
\text { study/validated }\end{array}$ \\
\hline $\begin{array}{c}\text { Beasley et al. } \\
(2005)^{(17)}\end{array}$ & $\begin{array}{l}\text { Evaluate validity of the DietMa- } \\
\text { tePro }{ }^{\mathrm{TM}} \text { program (PDA-based } \\
\text { software) and examine } \\
\text { sources of error from the } \\
\text { PDA-based food record. }\end{array}$ & $\begin{array}{l}\text { Thirty-nine adults (twenty-one } \\
\text { women, eighteen men; thirty- } \\
\text { six white, three black, one } \\
\text { Hispanic; mean age } 53 \text { years; } \\
\text { mean BMI } 28 \mathrm{~kg} / \mathrm{m}^{2} ; \text { mean } \\
\text { years of education } 16 \text { ). }\end{array}$ & $\begin{array}{l}\text { Three-day PDA-based food records } \\
\text { were compared with } 24 \mathrm{HR} \text { and } \\
\text { an observed, weighed and timed } \\
\text { lunch. } \\
\text { Sources of error were quantified by } \\
\text { using calories as the unit of com- } \\
\text { parison. }\end{array}$ & $\begin{array}{l}\text { No significant differences in daily totals for cal- } \\
\text { ories and macronutrients between PDA data } \\
\text { and comparison measurements. Pearson's } \\
\text { correlations for PDA and 24HR: } 0.5-0 \cdot 8 \text {; for } \\
\text { PDA data and observed lunch: } 0 \cdot 4-0 \cdot 8 \text {. The } \\
\text { largest source of absolute error in caloric } \\
\text { estimation was attributable to portion size } \\
\text { estimation error }(49 \%) \text {. }\end{array}$ & Yes \\
\hline Yon, $2006^{(18)}$ & $\begin{array}{l}\text { Investigate whether PDA use } \\
\text { for dietary self-monitoring } \\
\text { would reduce underreporting } \\
\text { prevalence and improve the } \\
\text { validity of self-reported energy } \\
\text { intake. }\end{array}$ & $\begin{array}{l}\text { Sixty-one white adults (fifty-six } \\
\text { women, five men; mean age } \\
48 \cdot 2 \text { years; mean BMI at } \\
\text { baseline } 32 \cdot 2 ; 66 \% \text { with uni- } \\
\text { versity degree). }\end{array}$ & $\begin{array}{l}\text { Part of } 24 \text { week in-person beha- } \\
\text { vioural weight control pro- } \\
\text { gramme. Provided with PDA } \\
\text { using Calorie King's }{ }^{\mathrm{TM}} \text { Handheld } \\
\text { Diet Dietary software. Energy } \\
\text { intakes from } 7 \mathrm{~d} \text { PDA food } \\
\text { records were collected within the } \\
\text { first month. Goldberg cut-off } \\
\text { values were used to classify indi- } \\
\text { vidual subjects as low energy, } \\
\text { valid or overreporters. Underre- } \\
\text { porting compared with prevalence } \\
\text { reported in literature. Question- } \\
\text { naires exploring PDA use col- } \\
\text { lected at baseline and } 6 \text { months. }\end{array}$ & $\begin{array}{l}\text { The prevalence of low-energy reporting } \\
\text { observed in the present study ( } 41 \%) \text { was } \\
\text { consistent with underreporting prevalence } \\
\text { reported in the literature }(27-46 \%) \text {. }\end{array}$ & No \\
\hline Wang, 2006 ${ }^{(19)}$ & $\begin{array}{l}\text { Evaluation of handheld PDA } \\
\text { with camera and mobile } \\
\left.\text { phone card (Wellnavi }{ }^{\mathrm{TM}}\right) \text {. }\end{array}$ & $\begin{array}{l}\text { Twenty-eight female university } \\
\text { food and nutrition students } \\
\text { (mean age } 19.3 \text { (SD0.5) } \\
\text { years; mean body weight } 53.3 \\
\text { (SD8.5) kg; mean BMI } 21.4 \\
\text { (SD2.9)). }\end{array}$ & $\begin{array}{l}\text { One-day WFR with subjects taking } \\
\text { digital photos of all recorded } \\
\text { foods, and photos sent to study } \\
\text { dietitians by mobile phone card. } \\
\text { An unannounced interview-admi- } \\
\text { nistered } 24 \mathrm{H} \text { R was carried out } \\
\text { the following day. Procedures } \\
\text { were repeated after } 6 \text { months. } \\
\text { Subjects completed a self-adminis- } \\
\text { tered questionnaire regarding the } \\
\text { three assessment methods. }\end{array}$ & $\begin{array}{l}\text { Differences between the Wellnavi }{ }^{\mathrm{TM}} \text { method } \\
\text { and WFR not statistically significant for most } \\
\text { of the thirty-three nutrients except } Z n, M n \text {, } \\
\text { vitamin } \mathrm{E} \text {, SFA, PUFA and dietary fibre. } \\
\text { Spearman correlation coefficients were } \\
\text { stronger for } 24 \mathrm{HR} v \text {. WFR (mean of two } \\
\text { periods measured }=0.77 \text { ) than for Wellna- } \\
\mathrm{vi}^{\mathrm{TM}} v \text {. FR (mean }=0.62 \text { ). } 57 \cdot 1 \% \text { of subjects } \\
\text { considered the Wellnavi }{ }^{\mathrm{TM}} \text { method to be the } \\
\text { least burdensome and the least time con- } \\
\text { suming, and } 42.9 \% \text { stated they could con- } \\
\text { tinue for a month using Wellnavi }{ }^{\mathrm{TM}} \text {. }\end{array}$ & Yes \\
\hline $\begin{array}{l}\text { Kikunaga, } \\
2007^{(20)}\end{array}$ & $\begin{array}{l}\text { Validation of a new dietary } \\
\text { assessment method, a PDA } \\
\text { with camera and mobile } \\
\text { phone card (Wellnavi }{ }^{\mathrm{TM}} \text { ) and } \\
\text { evaluation of the relation } \\
\text { between obesity and underre- } \\
\text { porting using Wellnavi }{ }^{\mathrm{TM}} \text {. }\end{array}$ & $\begin{array}{l}\text { Seventy-five healthy volunteers } \\
\text { (twenty-seven men, forty- } \\
\text { eight women, forty-three non- } \\
\text { obese and thirty-two obese; } \\
\text { aged } 30-67 \text { years). }\end{array}$ & $\begin{array}{l}\text { Subjects took digital photos of their } \\
\text { meals and had PDA display } \\
\text { option to write in ingredients of } \\
\text { dishes consumed. Data were } \\
\text { sent to the dietitian by a mobile } \\
\text { phone card. } \\
\text { Data were compared to data } \\
\text { obtained from WFR (five con- } \\
\text { secutive days). The association } \\
\text { between obesity and underreport- } \\
\text { ing using Wellnavi }{ }^{\mathrm{TM}} \text { was com- } \\
\text { pared with results from both WFR } \\
\text { and a motion and time study. }\end{array}$ & $\begin{array}{l}\text { The Wellnavi }{ }^{\mathrm{TM}} \text { method gave significantly } \\
\text { lower values for daily nutrient intakes in all } \\
\text { subjects than those obtained by the WFR, } \\
\text { except for some nutrients. Significant Spear- } \\
\text { man correlations }(0 \cdot 32-0.75) \text { for daily nutri- } \\
\text { ent intakes measured by Wellnavi }{ }^{\mathrm{TM}} \text { and the } \\
\text { WFR method in all subjects, except for } \\
\text { some nutrients. } \\
\text { Obesity in men was a factor of underreporting } \\
\text { but not in women. }\end{array}$ & Yes \\
\hline
\end{tabular}




\begin{tabular}{|c|c|c|c|}
\hline First author & Objective & Sample characteristics & Methods \\
\hline $\begin{array}{l}\text { Williamson, } \\
2003^{(21)}\end{array}$ & $\begin{array}{l}\text { Test the validity of digital photogra- } \\
\text { phy for measuring food portion } \\
\text { sizes compared with weighed } \\
\text { foods and with direct visual esti- } \\
\text { mation. }\end{array}$ & $\begin{array}{l}\text { Simulation of sixty meals } \\
\text { consisting of ten different } \\
\text { portion sizes from six } \\
\text { different university cafe- } \\
\text { teria menus was prepared } \\
\text { and weighed. }\end{array}$ & $\begin{array}{l}\text { Food selections and plate waste, as esti- } \\
\text { mated by digital photography and direct } \\
\text { visual estimation, were compared with } \\
\text { weighed foods. For each method, three } \\
\text { observers independently estimated por- } \\
\text { tion sizes as a percentage of a standard } \\
\text { serving. These percentages were multi- } \\
\text { plied by the weight of the standard por- } \\
\text { tion to yield estimated weights. }\end{array}$ \\
\hline
\end{tabular}

Results

Correlation study/validated

Pearson correlations with actual 0.97 for both digital photography and direct visual method. Correlations fo direct visual estimation (between 0.95 and 0.97 ) often significantly higher than those for digital photography (between 0.89 and 0.94). Both methods tended to yield small over- or underestimates.

Intra-class correlation coefficients for digital photography were 0.94 for food selection, 0.80 for plate waste and 0.92 for food intake, confirming good agreement among the three observers.

Martin, 2006 (22) Test the reliability and validity of digital photography for measuring children's food intake in a school cafeteria.
Lambert, $2005^{(23)} \quad$ Test the feasibility of using smart card technology to track eating habits of school children for a prolonged (several months) period of time.
Forty-three participants twenty girls; mean age 11.7 years; all AngloAmerican). (twenty-three boys and

Digital photography measured children's food intake at school lunch cafeteria for five consecutive days. Two registered dietitians estimated food selection, plate waste and food intake based on digital photography data. Photographs taken of weighed reference portions of each food item available.

Adiposity assessed with body impedance analysis and BMI expressed as percentile rank. Mood and self-esteem assessed with questionnaires.

Smart cards electronically recorded all transactions at the cash desk. During two 5-d trials (November and June), food choices were directly observed and recorded (plate waste) by researchers for 265 trays from sixty-five children. The data obtained by both methods were compared.

To test the relationship between foods chosen and actual amounts of food consumed, portion size of eighty foods was determined and variations in portion sizes and food wastage identified.
High degree of agreement observed between dietitians' estimates. Intraclass correlation coefficients for kilocalories selected and plate waste were both 0.95 and 0.93 for total kilocalories, and 0.93, 0.89 and 0.94 for fat, Pro \% and $\mathrm{CHO}$, respectively. Assessment over $3 \mathrm{~d}$ provided reliable and representative measure of intake.

A significant association between food intake and adiposity supported convergent validity. Non-significant correlations between food intake and depressed mood and self-esteem supported discriminant validity. Out of 265 trays, eleven yielding an accuracy rating of $95.9 \%$, had a significant discrepancy between food choices recorded by the researchers $v$. smart card data.

Prepared, processed food items showed low variation in portion size. Foods served by catering staff or diners had far greater variation. Some items produced far less wastage than others. Edible wastage correction factor needed for each food item in order to convert food choices into intake data. 